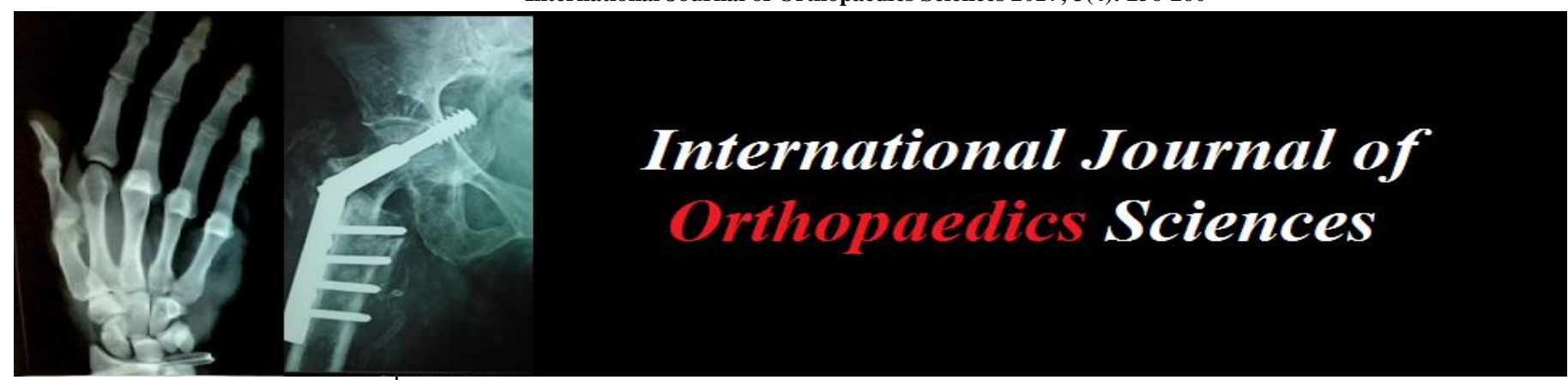

ISSN: $2395-1958$

IJOS 2017; 3(4): 256-260

(C) 2017 IJOS

www.orthopaper.com

Received: 15-08-2017

Accepted: 20-09-2017

Reda H Elkady

Orthopedic Department, Zagazig

University, Egypt

Nagi Fuda

Orthopedic Department, Zagazig

University, Egypt

\section{Percutaneous screw fixation of isolated fractures of the greater tuberosity of the humerus}

\author{
Reda H Elkady and Nagi Fuda
}

DOI: https://doi.org/10.22271/ortho.2017.v3.i4d.36

\begin{abstract}
Background: The unacceptable treatment outcome of the isolated greater tuberosity fracture of the humerus mainly due to missed diagnosis, ignorance, or when be trivialized.

Patients and Methods: Twelve patients with isolated, displaced fracture of the greater tuberosity of the humerus were treated with closed reduction and percutaneous fixation using one or two screws. The indication for surgery was $3-5 \mathrm{~mm}$ of displacement in any plane in a mean fragment without comminution. The cause of injury was sports in three patients, motor car accidents in five patients, and hyper abduction-external rotation of the shoulder during a fall in four patients.

Results: Radiographic union of the tuberosity was seen in all fractures. There was no heterotopic bone formation in any patient. Functional results were excellent in 8 patients (Constant score: $90.5 \%$ ), good in 2 patients (Constant score: $81.5 \%$ ) and satisfactory in 2 patients (Constant score: $70 \%$ ). All patients were satisfied with the outcome and the overall mean Constant score was $85.5 \%$.

Conclusion: Closed reduction and percutaneous fixation of large displaced fragment greater tuberosity fracture of the proximal humerus is a good technique providing stable fixation and less or no soft tissue complications as infection, muscle weakness, and adhesions. The technique should be done by experienced surgeon with intra-operative fluoroscopy. The screw is better used with washer for not to damage the fragment during compression.
\end{abstract}

Keywords: Percutaneous screw, isolated fractures, humerus

\section{Introduction}

Although fractures of the proximal humeral are common injuries, isolated displaced fractures of the tuberosities only account for a relatively small number ${ }^{[1]}$. Chun et al ${ }^{[2]}$ found that displaced greater tuberosity fractures accounted for 26 of 141 two-part fractures. Despite being a well-recognized clinical entity, the diagnosis of a greater tuberosity fracture is fairly commonly missed, ignored, or trivialized. This can result in an unacceptable treatment outcome. Perhaps it is the uncommon nature of this injury that leads to these problems, as many orthopaedic surgeons have only limited personal clinical experience with these injuries, and other health care providers may not be sufficiently aware of the significance of these injuries. Adequate understanding of these injuries is imperative. With the aging of our population and associated osteoporosis, these injuries may become more common and will require appropriate care ${ }^{[3,4]}$.

Isolated greater tuberosity fractures occur as the result of two different mechanisms of injury. They can occur as either impaction or avulsion and shearing injuries. In the former instance, there is usually direct impaction as might occur during a fall directly on the shoulder or with hyper abduction and impaction of the greater tuberosity against the acromion or superior glenoid. Avulsion injuries commonly occur in association with anterior glenohumeral dislocation. It has also been proposed that in some cases forceful pull by the rotator cuff can avulse the greater tuberosity ${ }^{[5]}$. Despite Neer's criteria for displacement, most authors agree that the shoulder has very little tolerance for greater tuberosity displacement ${ }^{[6]}$. McLaughlin suggested that displacement of greater than $5 \mathrm{~mm}$ may be problematic ${ }^{[7]}$. More recently, Park et al suggested that fractures with $3 \mathrm{~mm}$ of displacement should be reduced in athletes and heavy laborers who are involved in overhead activity. The effect of the direction of displacement is important. Superior displacement, which causes subacromial outlet impingement, is less well tolerated than posterior displacement ${ }^{[8]}$.

$$
\sim 256 \sim
$$


The procedure depends on the size and comminution of the tuberosity fragment. With multiple small fragments, internal fixation may prove difficult and primary rotator cuff-type repair through drill holes with heavy non-absorbable sutures or suture anchors is preferred. With a large tuberosity piece, fixation can be achieved using a screw with a washer to minimize comminution while tightening the screw. Percutaneous reduction represents an alternative to formal open approaches to minimize surgical site morbidity and improve cosmoses $[9,10]$. The aim of this prospective study was to give the results of treatment of 12 greater tuberosity fracture using percutaneous cannulated screw fixation in one main fragment without comminution.

\section{Patients and Methods}

Twelve patients with isolated, displaced fracture of the greater tuberosity were treated with closed reduction and percutaneous fixation using one or two screws according to the size of the fragment in the period from May 2005 to November 2009. Plain X-ray in three planes was used routinely for all patients to diagnose displacement of the tuberosity (Antero-posterior, Lateral, and Axillary views). The indication for surgery was $3-5 \mathrm{~mm}$ of displacement in any plane in a mean fragment without comminution. There were 8 males and 4 females. The ages ranged from 22 to 63 years, with an average of 46 years. The mechanism injury was avulsion injury to the greater tuberosity in 8 patients and as a result of shoulder dislocation in four patients. The cause of injury was sports in three patients, motor car accidents in five patients, and hyper abduction-external rotation of the shoulder during a fall in four patients. Four patients sustained concomitant anterior glenohumeral dislocation which was reduced before operation (Table 1).

The patients were evaluated by physical examination, and radiographs with a mean follow-up period of 18 months (Range 15- 30 months). True antero-posterior radiographs of the glenohumeral joint were assessed to determine union and the relation between the tuberosity and the head. The followup protocol included a subjective evaluation of pain and functional status by interview, evaluation of active and passive range of motion by clinical examination. In addition, each shoulder was scored using the Constant and Murley method of functional assessment of the shoulder ${ }^{[11]}$.

The result at follow-up was rated as excellent if the patient had no pain, had pre-injury functional status of the extremity, range of motion and muscle strength at least $90 \%$ compared to opposite side; as good if the patient was satisfied with the result, had pain only in the terminal range of motion, had preinjury functional status of the extremity, range of motion and muscle strength at least $75 \%$ compared to opposite side; and as satisfactory if the patient was satisfied with the result, had mild pain in the functional range of motion although not severe enough to necessitate analgesics, range of motion and muscle strength at least $50 \%$ compared to opposite side. An unsatisfactory result was one that failed to meet any of these criteria ${ }^{[8]}$.

\section{Surgical technique}

Under general anesthesia, the patients were positioned in the beach-chair position with the back tilted $40-60^{\circ}$ to the horizontal. The shoulder, arm and hand were prepared and draped. Percutaneous reduction was performed by manipulation under fluoroscopy guide, and then the limb was held in reduced position by the assistant. A small skin snip was done and provisional fixation was then performed using
Kirschner wires, over which cannulated screws with washers were advanced to fix the fragment. We used 2 screws in 7 patients and one screw in five patients (Figure 1).

\section{Postoperative Protocol}

The goals of operative reduction and internal fixation of a displaced greater tuberosity fracture are to achieve anatomic reduction and permit early range-of-motion exercises. We used arm to chest fixation with axillary padding for 2 weeks, then sling immobilization for 6 weeks to protect the fracture. After 6 weeks, active use and active range-of-motion exercises are initiated and passive stretching in all directions is emphasized. Specific rotator cuff strengthening against resistance was started at 12 weeks after surgery. Patients were advised that it may take up to 1 year to reach the end result.

\section{Results}

Radiographic union of the tuberosity was seen in all fractures (Figure 2). There was no heterotopic bone formation in any patient. Functional results were excellent in 8 patients (Constant score: $90.5 \%$ ), good in 2 patients (Constant score: $81.5 \%$ ) and satisfactory in 2 patients (Constant score: $70 \%$ ). All patients were satisfied with the outcome and the overall mean Constant score was $85.5 \%$; (Table 2). Active elevation of the shoulder ranged from 100 to $170^{\circ}$ (mean $140^{\circ}$ ). Active external rotation at $90^{\circ}$ of abduction ranged from 45 to $85^{\circ}$ (mean $70.5^{\circ}$ ). All patients were able to reach at least the second lumbar vertebral level in internal rotation (Figure 3). One patient needed second surgical procedure. This patient had presented with persistent, severe pain at two months after surgery with clinical signs suggestive of bicipital tendonitis. An open procedure for biceps tenodesis revealed impingement of a sharp medial edge of the greater tuberosity fragment against the biceps tendon. Excision of the impinging region of the fragment and tenodesis of the biceps tendon resulted in satisfactory pain relief. Four patients had moderate stiffness of the operated shoulder at 3 months after surgery, and were treated conservatively with reassurance, physiotherapy and occasional intra-articular injections of steroids. At the final follow-up, two of the four patients had a good result and two had a satisfactory result. There were no neurological complications, infections or complications of wound healing.

\section{Discussion}

Isolated greater tuberosity fractures are well described and frequently discussed; however, there are only very limited published follow-up data about the surgical treatment of displaced fractures ${ }^{[12-14]}$.

Most authors have reported that non-operative treatment of displaced greater tuberosity fractures has a poor outcome; Santee [14] observed that even slight displacement of the greater tuberosity can result in disability. McLaughlin [7] found that patients who had greater than $1 \mathrm{~cm}$ of displacement had significant disability and that even patients with between 0.5 and $1 \mathrm{~cm}$ of displacement had a prolonged recovery, requiring a reconstructive procedure in $20 \%$ of cases. Although Young and Wallace ${ }^{[15]}$ reported good and acceptable results in 7 patients treated non-operatively, they did not use stringent criteria for shoulder motion. Nevertheless, their patients were satisfied with the function and had no pain. The indication for surgery was at least $5 \mathrm{~mm}$ of displacement in any plane.

Braunstein $\mathrm{V}$ et al ${ }^{[16]}$ performed biomechanical testing of the three most common surgical techniques for fixation of greater 
tuberosity fractures of the humerus: tension banding osteosynthesis, fixation with two screws, and trans-osseous sutures. They founded no significant differences between tension-banding and two cancellous screws, but both techniques showed significantly higher values than fixation with trans-osseous sutures. The two screws when placed percutaneously after an adequate closed reduction allow maximum soft tissue preservation; however, this procedure is technically demanding. Heavy non-absorbable sutures may be used for three- and four-part fractures of the proximal humerus as well as greater tuberosity fractures as it avoids sharp deep soft tissue dissection and the hard-ware associated dangers of other fixation methods as subacromial impingement or fragment damage ${ }^{[17]}$.

Percutaneous reduction and fixation has been used for the fixation using cannulated screws ${ }^{[14]}$. Although this approach has the advantage of being a less invasive technique, it has the disadvantage of fixation with pins or screws, both of which have been associated with failure of open reduction and internal fixation ${ }^{[18]}$.

The surgical technique described in our study using percutaneous screw fixation of non-comminuted displaced greater tuberosity fracture; this technique was found effective, less invasive with less soft tissue complications as infection, muscle weakness, and adhesions, and the functional results were between excellent ( 8 patients), good ( 2 patients), and satisfactory (2 patients).

In a study by Park et al ${ }^{[8],}$ they concluded that the long-term results of open reduction and internal fixation of displaced tuberosity fractures are comparable to those described in literature for displaced tuberosity fractures ${ }^{[6,10]}$. Eighteen patients in this study had a good or excellent result and only one patient had an unsatisfactory result. There was, however, a higher incidence of complications in the post-operative period necessitating a second surgical procedure in three patients and prolonged rehabilitation with additional intraarticular injections in five patients.

Impingement of the biceps tendon by the medial edge of the tuberosity fragment and a foreign body reaction to the fixation material, each resulting in severe, persistent pain with active motion in the rehabilitation period are unusual complications [12].

One patient from twelve in our study encountered impingement of biceps tendon expected when the patient suffered from severe pain two months post-operative, and open exploration was done with tenodesis of biceps tendon after removal of hard bone making the impingement.

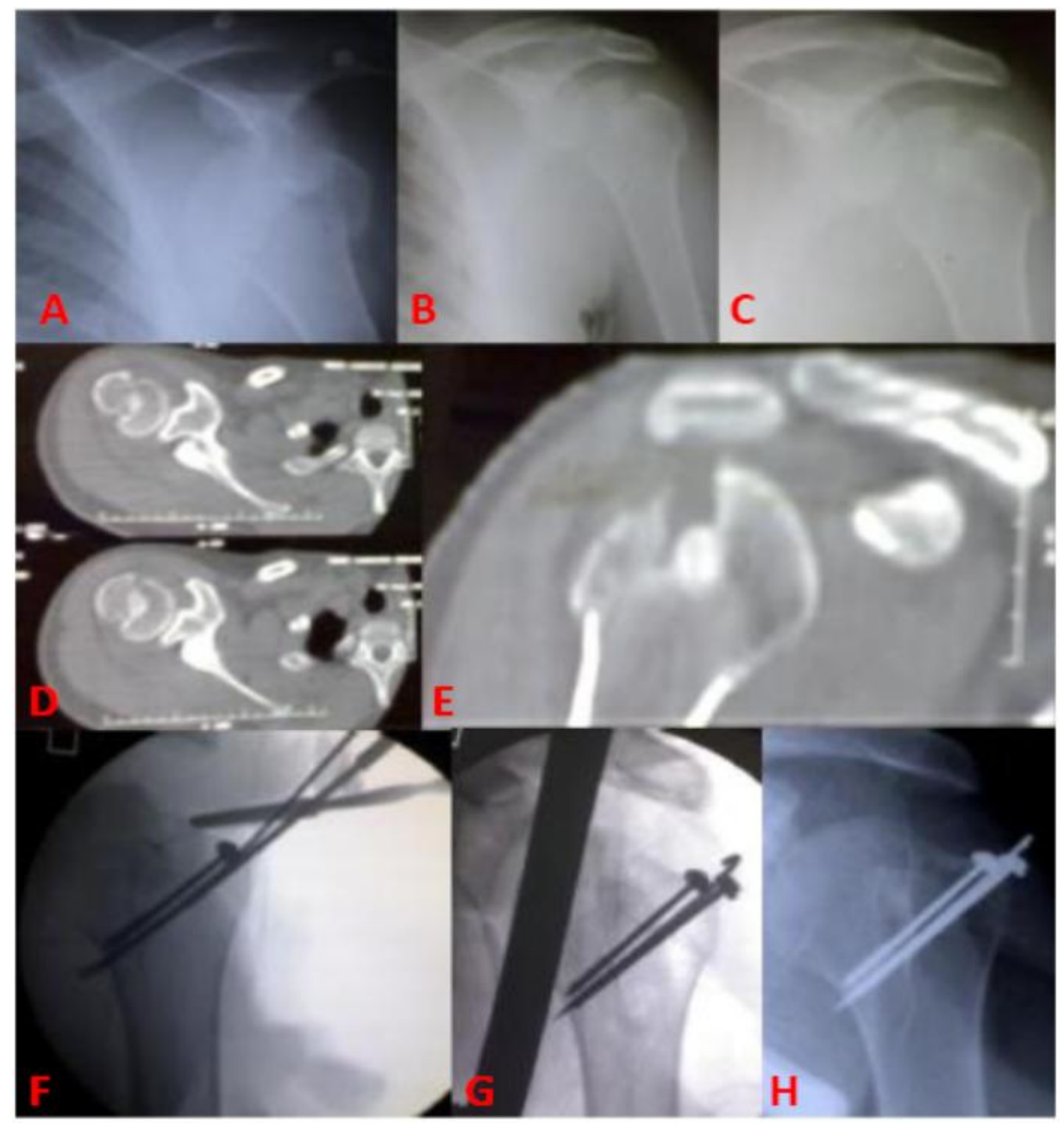

Fig 1: Operative technique; A) Preoperative X-ray with fracture dislocation of the shoulder; B\&C) X-ray after reduction of the dislocation showing fracture of greater tuberosity; D\&E) Post-reduction C-T scan of the shoulder confirm fracture with displacement; F\&G) Intraoperative $\mathrm{X}$-ray during screw fixation; $\mathrm{H}) \mathrm{X}$-ray 3 months postoperative. 


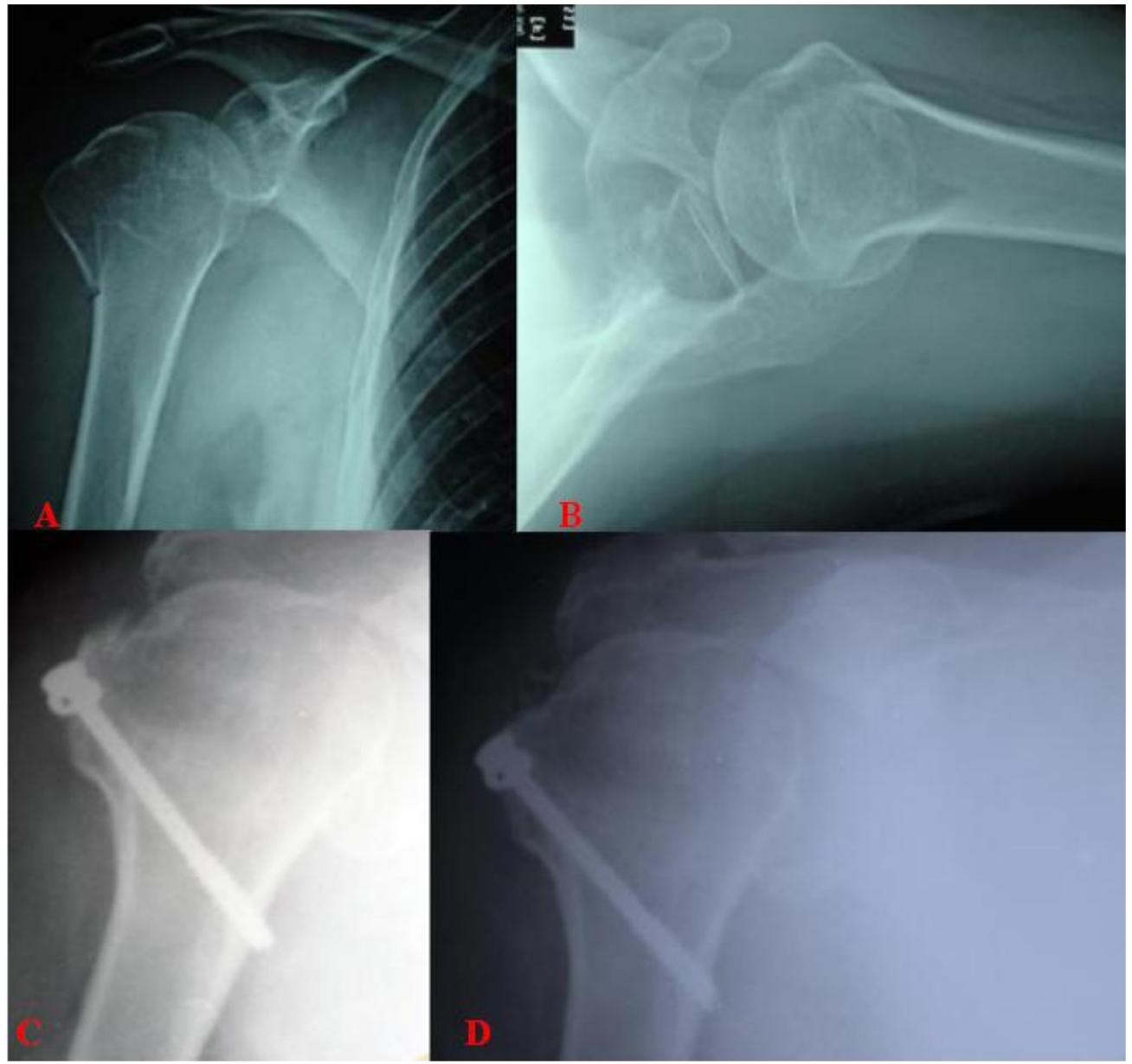

Fig 2: $\{$ Case No. 3\}: A\&B) Preoperative X-ray; C) X-ray 3 months postoperative; D) X-ray 15 months postoperative.

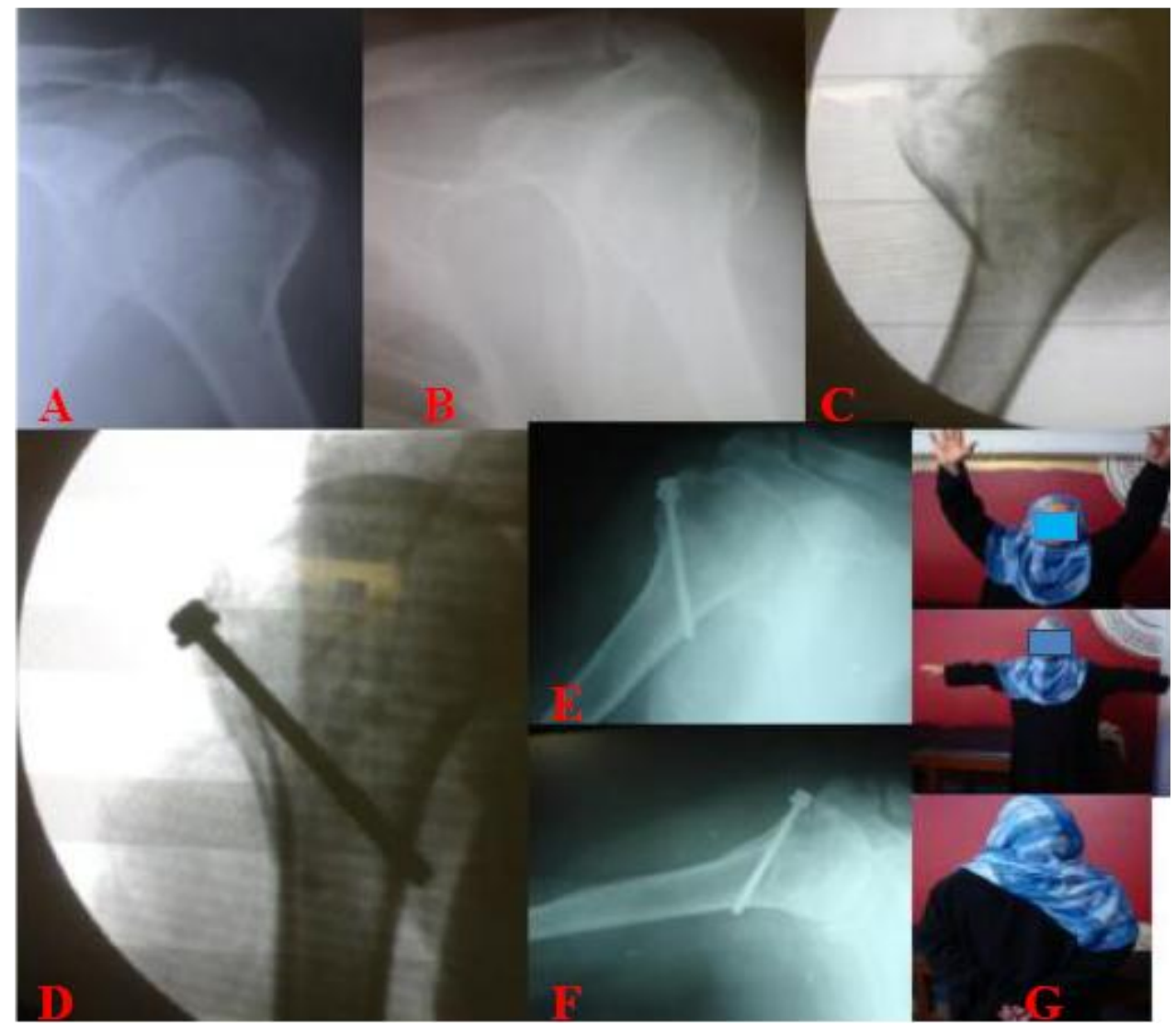

Fig 3: $\{$ Case No. 5\}: A\&B\&C) Preoperative X-ray; D) Intraoperative X-ray; E) X-ray 3 months postoperative; F) X-ray 1year postoperative; G) Clinical result of the patient at the end of follow up. 
Table 1: Demographics of the patients

\begin{tabular}{|c|c|c|c|c|c|c|}
\hline $\begin{array}{c}\text { Patient } \\
\text { No. }\end{array}$ & Age & Sex & $\begin{array}{c}\text { Mechanism of } \\
\text { injury }\end{array}$ & Cause of trauma & $\begin{array}{c}\text { Follow up } \\
\text { period-(months) }\end{array}$ & $\begin{array}{c}\text { Duration between injury and } \\
\text { operation(days) }\end{array}$ \\
\hline 1 & 55 & Male & Avulsion & Accident & 30 & 5 \\
\hline 2 & 35 & Male & Dislocation & Sports & 22 & 3 \\
\hline 3 & 63 & Male & Avulsion & Fall/hyper- abduction & 24 & 4 \\
\hline 4 & 22 & Male & Dislocation & Sports & 18 & 7 \\
\hline 5 & 53 & Female & Avulsion & Accident & 30 & 3 \\
\hline 6 & 56 & Female & Avulsion & Fall/hyper- abduction & 21 & 8 \\
\hline 7 & 50 & Male & Avulsion & Fall/hyper- abduction & 25 & 6 \\
\hline 8 & 42 & Male & Dislocation & Accident & 24 & 4 \\
\hline 9 & 50 & Female & Avulsion & Fall/hyper- abduction & 20 & 6 \\
\hline 10 & 46 & Male & Avulsion & Accident & 18 & 8 \\
\hline 11 & 37 & Female & Dislocation & Sports & 18 & 2 \\
\hline 12 & 43 & Male & Avulsion & Accident & 15 & 4 \\
\hline
\end{tabular}

Table 2: Results of the patients at final follow up

\begin{tabular}{|c|c|c|c|c|c|}
\hline & \multirow[b]{2}{*}{ Union of the fracture } & \multicolumn{3}{|c|}{ Functional results/ Mean Constant score } & \multirow[b]{2}{*}{ Complications needed reoperation } \\
\hline & & $\begin{array}{l}\text { Excellent } \\
(90.5 \%)\end{array}$ & $\begin{array}{c}\text { Good } \\
(81.5 \%)\end{array}$ & $\begin{array}{c}\text { Satisfactory } \\
(\mathbf{7 0 . 5 \% )}\end{array}$ & \\
\hline No. of patients & 12 & 8 & 2 & 2 & 1 \\
\hline Total patient No. & 12 & 12 & 12 & 12 & 12 \\
\hline Percentage $\%$ & $100 \%$ & $67 \%$ & $16.5 \%$ & $16.5 \%$ & $8.3 \%$ \\
\hline
\end{tabular}

\section{Conclusion}

Closed reduction and percutaneous fixation of large fragment displaced greater tuberosity fracture of the proximal humerus is a good technique providing stable fixation and less or no soft tissue complications as infection, muscle weakness, and adhesions. The technique should be done by experienced surgeon with intraoperative fluoroscopy. The screw is better used with washer for not to damage the fragment during compression.

\section{References}

1. Johnson JR, Bayley JIL. Early complications of acute anterior dislocation of the shoulder in the middle-aged and elderly patient. Injury. 1982; 13:431-434.

2. Chun JM, Groh GI, Rockwood CA. Two-part fractures of the proximal humerus. J Shoulder Elbow Surg. 1994; 3:273-287.

3. Hall MC, Rosser M. The structure of the upper end of the humerus with reference to osteoporotic changes in senescence leading to fractures. Can Med Assoc. 1963; 88:290-294.

4. Horak J, Nilsson BE. Epidemiology of fractures of the upper end of the humerus; Clin Orthop. 1975; 112:250253.

5. Gibbons AP. Fracture of the tuberosity of the humerus by muscular violence. BMJ. 1909; 7:1674-1679.

6. Neer CS. II: Fracture classification systems: do they work and are they useful? [Letter; comment]. J Bone Joint Surg Am. 1994; 76:789-790.

7. McLaughlin HL. Dislocation of the shoulder with tuberosity fracture. Surg Clin North Am. 1963; 43:16151620.

8. Park TS, Choi IY, Kim YH. A new suggestion for the treatment of minimally displaced fractures of the greater tuberosity of the proximal humerus. Bull Hosp Jt Dis 1997; 56:171-176.

9. Jakob RP, Kristiansen T, Mayo K, Ganz R, Muller ME. Classification and aspects of treatment of fractures of the proximal humerus. In: J.E. Bateman and R.P. Welsh, Editors, Surgery of the shoulder, Mosby, St. Louis. 1984, 330-343.
10. Gartsman GM, Taverna E, Hammerman SM. Arthroscopic treatment of acute traumatic anterior glenohumeral dislocation and greater tuberosity fracture. Arthroscopy. 1999; 15:648-650.

11. Constant CR, Murley AH. A clinical method of functional assessment of the shoulder, Clin Orthop Relat Res. 1987; 214:160-164.

12. Flatow EL, Cuomo F, Maday MG. Open reduction and internal fixation of two-part displaced fractures of the greater tuberosity of the proximal part of the humerus, $J$ Bone Joint Surg Am. 1991; 73(8):1213-1218.

13. Green A, Izzi J Jr. Isolated fractures of the greater tuberosity of the proximal humerus, J Shoulder Elbow Surg. 2003; 12(6):641-649.

14. Santee HE. Fractures about the upper end of the humerus. Ann Surg. 1924; 80:103-114.

15. Young TB, Wallace WA. Conservative treatment of fractures and fracture-dislocations of the upper end of the humerus; J Bone Joint Surg Br. 1985; 67:373-377.

16. Braunstein V, Wiedemann E, Plitz W, Muensterer OJ, Mutschler W, Hinterwimmer S. Operative treatment of greater tuberosity fractures of the humerus A biomechanical analysis; Clinical Biomechanics. 2007; 22:652-657.

17. Resch DS, Hubner C, Schwaiger R. Minimally invasive reduction and osteosynthesis of articular fractures of the humeral head; Injury 32(Suppl 1):25-32.

18. Green A, Norris T. Complications of non-operative management and internal fixation of proximal humerus fractures. In: E. Flatow and C. Ulrich, Editors, Musculoskeletal trauma series-humerus, ButterworthHeineman, Oxford. 1996, 106-120. 